\title{
Can Lean Thinking Enhance The Performance Management Of Micro-Enterprises? A Case Study in Lima, Peru
}

\author{
Chung-Jeng Huang ${ }^{1 *}$, Elisa Denisse Talla Chicoma ${ }^{1 *}$ and Yi-Hsien Huang ${ }^{2}$
}

${ }^{1}$ Department of Industrial Engineering and Management, National Kaohsiung University of Science and Technology, Kaohsiung 80778, Taiwan, ROC

${ }^{2}$ Department of Business Administration, National Kaohsiung University of Science and Technology, Kaohsiung 80778, Taiwan, ROC

*Corresponding authors

\begin{abstract}
Ineffective management affects retail cost that results in high retail prices causing some struggles in the families that perceive a low income. In Peru, part of the food trade is carried out through retailers, in neighborhood markets or street vendors, making the fresh vegetables very popular stores in the markets of Lima. But, the price of these vegetables, in some cases, is very high in comparison with the original price. In a way to solve this problem, a group of 15 micro-enterprises was evaluated in a way to provide a solution to this problem. The method applied was based on the three main principles of Lean Thinking (eliminate waste, simplify everything and create flow) and was designed in 4 stages, first, describe the initial situation, second, identify critical situations, third, Define Objective and Scope of analysis and fourth, action plan to improve the current situation. As results of this study, the number of hours was fall down in $33 \%$, from 18 to 12 hours per day and also the tools provided helped to change the way of thinking of micro-entrepreneurs, to understand that organizing they work environment and removing activities that do not add value to the process can generate beneficial outcomes for them as employees and also for the business. This study could be the base for further research projects focused in Micro-Enterprises in developing countries.
\end{abstract}

Keywords: Lean Thinking, Strategic Management, Micro-Enterprises, Continuous Improvement

\section{Introduction}

The Micro and Small Enterprises (MSEs) is a sector that emerges as a socio-economic phenomenon that has been transformed over the last years by the economies of most countries worldwide, mainly from developing countries, as a response to many unmet needs by lowincome sectors of the population.

Micro-enterprises play an important role as a powerful tool to combat poverty and to empower low-income households economically(Al Mamun, Ibrahim, Yusoff, \& Fazal, 2018). They also play an important role in competitiveness, the development of new technologies and providing support for big companies(Huang, 2009). 
One of the most favorable points of these small businesses is that if they grow in size, the economy of the country will be affected and as a consequence, the levels of poverty will decrease. However, the real situation is that in some cases their productivity and performance remains low for several years. While their low performances may be attributed to the unfavorable circumstances surrounding them, past studies have identified problems within firms, especially problems regarding management(poor management practices), finance(cost of finance or access to finance) and lack decision making (Bloom, Mahajan, McKenzie, \& Roberts, 2010).

Micro and Small Enterprises in Peru, face many obstacles to its development such as problems of access to markets, technological barriers and difficulties in obtaining credit facilities from the financial sector (Zevallos, 2010). Sometimes, the income of these companies just allows the owners to cover basic needs, such as food, housing and in the lucky of the cases education. Therefore, these companies do not have the possibility of generating profits or increasing their productivity.

In Peru, $75 \%$ of the food trade is carried out through retailers, in neighborhood markets or street vendors. Unfortunately, even this supply chain although seeks to bring the product closer to the final consumer, often affect them because the price is very high in comparison with the wholesaler, for example in the wholesale market of the kilogram of a vegetable $\mathrm{X}$ costs 2.50 PEN, and retail 4.50 soles. But in the district or neighborhood markets, it costs 9.00 PEN per kilogram, so, the profit margins of the retailers are sometimes over exaggerated (ANDINA, 2018).

The economy of these times calls supply chains to be more efficient and sustainable (Beamon, 1999). A very well-known concept called Lean methodology is an approach that can help organizations improve efficiency, reduce waste, and attain sustainability. The lean concept of 'reduction of waste' is well amenable to sustainability practices across supply chains (Wu et al., 2015). This concept is no longer limited to the manufacturing sector, service enterprises have started to adopt lean management for process improvement (Hussain \& Malik, 2016).

Pearce, Pons, \& Neitzert (2018) describes specific factors that were influential in the success or failure of lean founded in some cases of study, these are limited resources for SMEs, resistance to change, employee engagement or lack of persistence, among others.

Mohan Sharma \& Lata (2018), presents a case of study based on the effective implementation of $5 \mathrm{~s}$ in a copper wire drawing company based in East of the National Capital Territory of Delhi, India. The paper shows how this tool eliminates the waste and improves the efficiency, environmental performance, housekeeping, health and safety in the enterprise.

Matt \& Rauch (2013) presents a case of study where the introduction of Lean methods brought improvements and advantages in a small company with 25 employees in Italy.

Based on the information provided by previous studies, was designed a 3 Modules Program to improve the performance of a Micro-Enterprise based on the concept of Lean Thinking. The implementation of lean tools can bring many benefits in any type of organizations, such as reducing waste and improving operating efficiency just for cited two of them. However, lean implementation is not an easy or quick process, is a continuous process that involves people commitment.

It is important to mention that two problems were an affront in this study; the first one is that although a number of successful cases have been presented in the past years, most of the 
developed methodologies are designed just for large or medium size organizations; this case is a Micro-Enterprise. The second one is that some of the existing Micro-enterprises in Peru were created in a very empirical model, without any basic-level of management, with the only purpose to support the economy of their family, as a consequence, many of these enterprises do not have an idea of the opportunities for improvement that exist for their business, make a change is considered "frightening", because they don't have any idea of how successful the results could be, or a "waste of time", because they are too busy in their daily routine that they do not have time to implement changes.

The aim of the present research is to prove that is possible to introduce the concept of Lean Thinking and implement a Program in a Micro-Enterprise that improves the management performance redefining the business goals and objectives.

The paper is organized as follows. Section 2 is provided a review of the literature. Section 3 is presented the research method that explained the case of study, followed by Section 4 presents the results of the study. Finally, the paper ends with our conclusions and recommendations.

\section{Literature Review}

\subsection{Lean Thinking}

Lean thinking has developed into a management philosophy that focuses on increasing effectiveness. The lean methodology has enabled Toyota to become the world's leader in quality and process efficiency (J.P. Womack \& Jones, 2010). According to Bhamu \& Singh Sangwan (2014), lean provides a methodology that can significantly improve the responsiveness to customers while reducing and waste and operational procedures.

Although the service and manufacturing sectors are different in many factors, the optimization of value-adding and non-value adding activities, ensuring built-in quality, standardizing and simplifying processes is equally valid for both.

The publication of Womack and Jones (James P. Womack, 1996), have been used as fundamental guides for lean transformation consolidating lean thinking into five lean principles as shown in Figure 1.

Figure 1: Diagram of 5 principles of Lean, defined by Womack 
Based on five lean principles, the lean approach is also about clear identification of customer value, which is the starting point in a lean system. The customer value in its turn leads to waste identification and creation of flow (James P. Womack, 1996).

\subsection{Lean Thinking in Services}

Sampson \& Froehle (2006) define the concept of "service" as the following: "While a product is a thing, a service is an activity - a process or a set of steps - which involves the treatment of a customer (or user) or something belonging to them, where the customer is also involved, and performs some role in the service process (also referred to as the service delivery process)." A remarkable difference with manufacturing is that the customer is able to see the service process and in many cases plays an important role (Gronroos, 2007; Johnston, Clark, \& Shulver, 2012). In contrast, most customers do not get to see a manufacturing process and generally do not get involved in it. The case of service process they role is as coproduction or co-creation (Johnston et al., 2012).

Lean makes a statement about what is desirable (e.g. value creation, smooth flow of materials) and what is undesirable (waste). Lean is also an instrument for problem-solving and action. In this paper, lean is therefore viewed as a normative and pragmatic theory of operations management. These conditions are present for many service processes, including administrative processes, which is the type of service this paper focuses on.

This paper focuses on the first three principles of Lean Thinking and has been applied in the case of study as part of the Improvement Program implemented in Micro Enterprises.

\section{Research Method}

The core of this research is to develop a Method based on the concept of Lean Thinking applied in a Micro-enterprise with the main purpose of encouraging their owner (entrepreneurs) to use this concept in a way to improve their business performance management.

Message Costa, Filho, Fredendall, \& Gómez Paredes (2018), studied 28 papers related to the implementation of Lean and Six Sigma in the food industry and founded that are 3 key 
steps basic fort the implementation. The first step, Pre-implementation, includes analyses of the implementation team. The second step, called Implementation, analyzes the drivers of adoption, the tools and methods, the critical success factors, the barriers, and the benefits. Finally, the last step, Post-Implementation, which examines the results of the continue/sustain actions to maintain and sustain the initiatives.

Based on the pillars of Lean Thinking, a methodology of 5 stages was developed, as shown in Figure 2.

Source: Authors

Figure 2: Case of Study Proposed Method

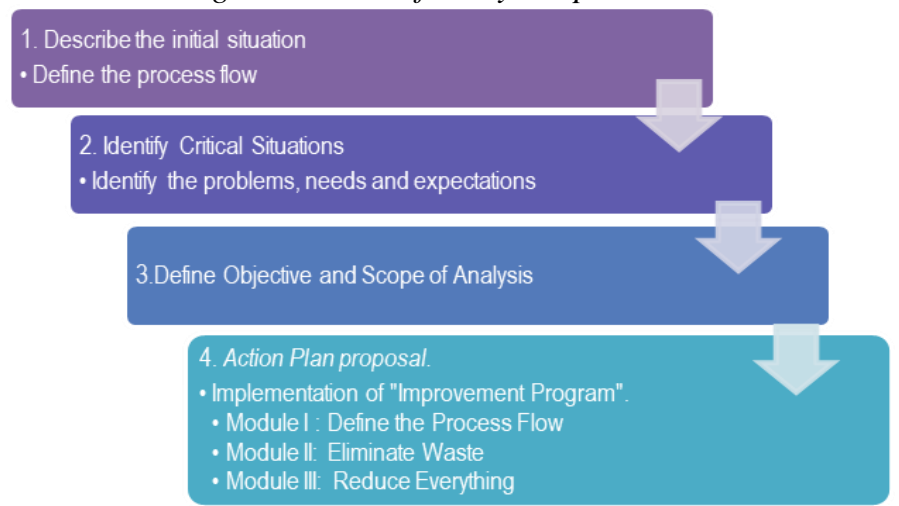

\subsection{Implementation of the research method}

After interviewed 15 microenterprises, was selected one as our case, the main reason was the predisposition and enthusiasm that they show to us at the moment of the interview, and also they recognize that needed help to improve their business conditions.

As many of the micro enterprises in Peru, the selected enterprise faces different challenges to its development such as problems of access to new markets (they actual market is very small), technological barriers, management skills and difficulties in obtaining credit facilities from the financial sector.

The selected case is a micro-enterprise located in Lima, Perú. Was founded in 2001, and as many of the fresh food stands in Peru is part of a small market located in the district of Lima, Cercado de Lima. It is a family business, the mother is the owner, she works with her elder daughter, together coordinate the daily activities and manage the business, also other members of their family support this business but is very random. The names of the owners and the business have not been revealing in a way to protect their privacy.

\subsubsection{Stage 1. Describe the Initial Situation}

"If you cannot describe what you are doing as a process, you do not know what you are doing" (W. Edwards Deming)

First, a format was elaborated to gather the information by level of importance. From the processed information, a Process Flow Diagram was prepared in a way to understand the activities involved in the business operation. To make the process more understandable, the 
activities of the business have been divided into 5 Stages, which are represented in the followed Figure 4.

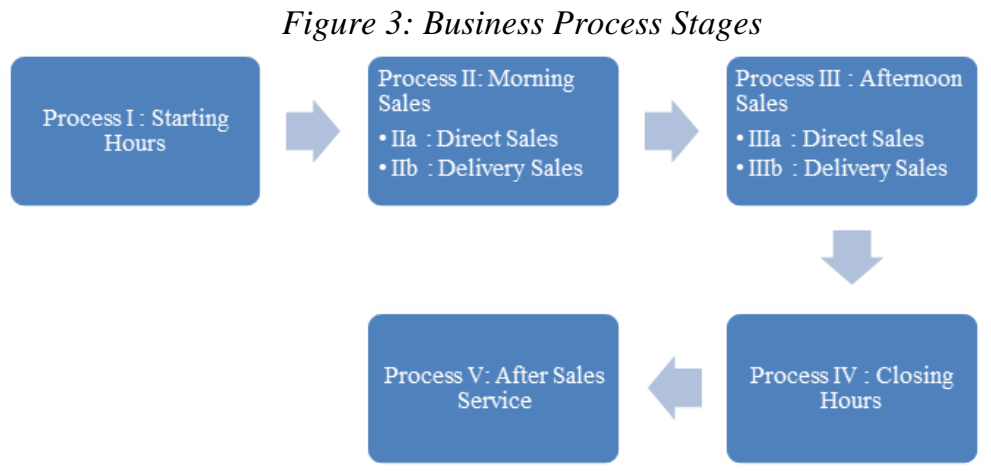

Source: Authors

On Table 1 the schedule of working hours of the business has been described, starting very early in morning 4:30 am, the reason is that time the freshest vegetables are available, so in a way to ensure the request of the order from the clients the owner has to arrive early to the Wholesale Vegetable Market. On the other side, the orders are received until midnight because, as the owner explained, the only way to receive them is by phone calls or messages. The number of hours of work is a total of 18 hours and the activities are divided between 3 persons.

Table 1: Resume of total hours of work

\begin{tabular}{|c|c|c|c|}
\hline Name of the stages & \multicolumn{2}{|c|}{ Schedule } & Number of hours \\
\hline The process I: Starting hours & $04: 30 \mathrm{am}$ & $08: 00 \mathrm{am}$ & 3.5 hours \\
\hline Process II: Morning sales & $08: 00 \mathrm{am}$ & $13: 00 \mathrm{pm}$ & 5 hours \\
\hline Process III: Afternoon sales & $13: 30 \mathrm{pm}$ & $06: 00 \mathrm{pm}$ & 4.5 hours \\
\hline Process IV: Closing hours & $06: 00 \mathrm{pm}$ & $07: 00 \mathrm{pm}$ & 1 hour \\
\hline Process V: After sales service & $08: 00 \mathrm{pm}$ & $12: 00 \mathrm{pm}$ & 4 hours \\
\hline \multicolumn{2}{|r}{} & Total: & 18 hours \\
\hline
\end{tabular}

\section{Source: Authors}

The working days are from Monday to Sunday, and just take 10 days off per year, causing very high levels of stress over the owners who although are family members, have to face some confrontations that lead to a bad work environment.

\subsubsection{Stage 2. Identify critical situations}

After understanding the initial scenario of the business, the critical points of the business were identified.

a) Value: They did not know their value as a business. 
b) Inventory: Was found a lack of Inventory Planning, causing over-inventory sometimes, giving as a consequence a waste of products, because in case of vegetables or fresh food, in general, the period of time is very short in comparison with other products.

c) Internal Organization: It was found a lack of internal organization, internal standards were not defined. The relationship with suppliers and customers were not strategic alliances.

d) Lack of Knowledge of the market: The lack of knowledge of their competitors and their potential customers just allow them to keep selling their products to the same market and also does not allow the application of marketing techniques.

e) Planning: They does not review the current operations of the business as a consequence they cannot identify what could be improved operationally, having a very low level of decision making, losing possible opportunities to increase their number of sales.

f) Lack of Technological Innovation: There are few systems designed specifically for microenterprises and most of them do not have a good capacity for adaptation, which means the businesses cannot develop their full potential.

\subsubsection{Stage 4: Define the Objective and Scope of Analysis}

The business does not have a historical record of their number of sales, list of products or prices. So the definition of cost drivers to define strategies and opportunities of improvement was excluded.

After clarifying that point, was decided to address this case proposing a very clear objective: To define a program that allows this business to reduce their working hours and improve the way they operate the business.

\subsubsection{Stage 5: Action Plan to improve the current situation}

A program composed of 3 Modules as Figure 4 illustrates was proposed.

Figure 4: Improvement Program-Duration 11 weeks

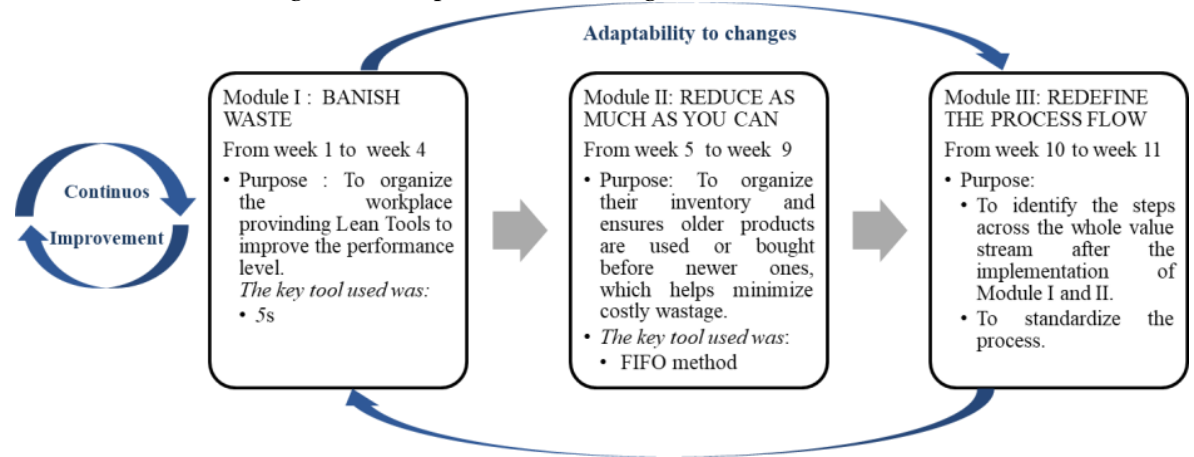

Source: Authors

\section{Results}

The presented Program demonstrates that the three pillars of lean thinking summarized in eliminate waste, simplify everything and create flow can be introduced in a Micro-Enterprise, the only condition is that the business must be open to making changes in the way they work, collaboration and compromise are the keys to the successful implementation of the program. 
The results of this study illustrate the existing hidden potential in micro-enterprises in Peru. In the case of Module I the main purpose was to organize the workplace providing lean tools to improve the performance level. The implementation of $5 \mathrm{~S}$ is considering the best tool to introduce the concept of Lean to a business that has a very low level of Management Knowledge. This module reduced the Process IV called "Closing hours", in coordination with the owner was decided to stop selling products in this stage (between $6 \mathrm{pm}$ to $7 \mathrm{pm}$ ), for instance, that activity was replace by do inventory inspection and control, changing the first activity of the day as the last activity of the day (saving 1 hour at morning and 30 minutes at night). Also, in this module the time to receive orders changed; this was done with the support of the owner who decided to coordinate with the clients in a way to establish the rules of the business. At the first week was a little difficult to set the change, because the clients had a routine to do late orders, but a price strategy was set, a $10 \%$ of increase over the price in all the orders after 11:00 pm. This strategy was achieved with good results, because of the high level of loyalty of the clients and most of all because of the high level of quality that the business offer, also the clients see the opportunity to get a discount, opportunity that the business gives for the first time.

In the case of Module II, the main purpose was to organize their inventory and ensures older products should be selling before newer ones, which helps minimize costly wastage. The considered tool was First In - First Out that in sum with $5 \mathrm{~S}$ reduce wastage of vegetables on the store. In this Module, customer satisfaction was improved because the vegetables were an organizer in a strategic way (easy to find), and discounts were offer for products that were soon to date. Finally, after seeing good results in the first module, the time to receive orders was changed again (From 09:00 to 11:00 pm), a fixed schedule. And a price strategy was applied again, but in this case was offered a reward consisted in 5\% of discount over the price in all the orders between 09:00 pm to 11:00 pm, but also the 10\% of increase over the price in all the orders after 11:00 pm was kept. This strategy helped the clients to follow a rule; the after sales services now become a controlled process that changed from 3 hours to 2 hours of work.

In Module III the main purpose was to purpose was the standardization of the process, after the definition of the correct activity per process will be clear for the owner understands which activities are adding or reducing the value to the business. Standardized work does not just happen to define the value stream. It is necessary to define a leader, a person who will naturally guide the team to achieve goals together. The standardization process is the last but not the final step is just the definition of 'the best way to do it', but has to be redefined as soon any improvement has been founded in a way to preserve the idea of Continuous Improvement.

Finally, Table 5 shows a summary of the numbers of hours were reduced between the 11 weeks of the Improvement Program.

Table 2: Resume of total working hours reduced

\begin{tabular}{|c|c|c|c|}
\hline Stages & Before & After & $\begin{array}{c}\text { Number of } \\
\text { hours reduced }\end{array}$ \\
\hline Process I : Starting Hours & $\begin{array}{c}04: 30 \mathrm{am}-08: 00 \mathrm{am} \\
3.5 \text { hours }\end{array}$ & $\begin{array}{c}05: 30 \mathrm{am}-08: 00 \mathrm{am} \\
2.5 \text { hours }\end{array}$ & 1 hour \\
\hline Process II: Morning Sales & $\begin{array}{c}08: 00 \text { am }-13: 00 \mathrm{pm} \\
5 \text { hours }\end{array}$ & $\begin{array}{c}08: 00 \mathrm{am}-13: 00 \mathrm{pm} \\
5 \text { hours }\end{array}$ & \\
\hline
\end{tabular}




\begin{tabular}{|c|c|c|c|}
\hline Process III: Afternoon Sales & $\begin{array}{c}13: 30 \mathrm{pm}-06: 00 \mathrm{pm} \\
4.5 \text { hours }\end{array}$ & $\begin{array}{c}13: 30 \mathrm{pm}-04: 00 \mathrm{pm} \\
2.5 \text { hours }\end{array}$ & 2 hours \\
\hline Process IV : Closing Hours & $\begin{array}{c}06: 00 \mathrm{pm}-07: 30 \mathrm{pm} \\
1.5 \text { hour }\end{array}$ & $\begin{array}{c}\text { 04:30 pm - 05:00 pm } \\
0.5 \text { hour }\end{array}$ & 1 hour \\
\hline Process V: Customer & $\begin{array}{c}08: 30 \mathrm{pm}-12: 00 \mathrm{pm} \\
\text { Service }\end{array}$ & $\begin{array}{c}\text { 09:00 pm - 11:00 pm } \\
2 \text { hours }\end{array}$ & 1 hour \\
\hline Total of hours & 18 hours & 13 hours & 5 hours \\
\hline
\end{tabular}

Source: Authors

\section{Conclusions}

The findings of this study has several theoretical and practical implications. From the theoretical perspective, the study provided an exploration of lean thinking tools in fresh vegetable stores or even micro-enterprises. Unlike previous studies that explored small and medium enterprises, this study has investigated the case of a micro-enterprise which did not provide record data to prepare a deep analysis. From the practical perspective, the implemented methodology involved teamwork and active participation of employees, at the same time, the most important benefits were the creation of a better and safe work environment, increase the levels of motivation of the employees, elimination of waste, time savings and overall the implementation of $5 \mathrm{~S}$ and FIFO Storage System, demonstrating that the size of the business does not restrict the application of Lean.

This study brings the opportunity to connect business that for many years worked in one way and were not open to new ideas with opportunities that not only improve their performance also redesign the idea of a business that owners had.

Daily results of both sales and inventory should be recorded to permit evaluate results and analyze the progress of the business. Is recommended that the next step for this business would be the implementation of a system that allows them to track the sales and prices, and also obtain digital invoices.

The methodology does not finish with the implementation of the tools, the training have to continue with the support of the owner, is about continuous improvement, so from now and ahead the owner of the business has to track their progress and every certain time prepare an Improvement Program again in a way to obtain time-sustained results.

Training programs are a very critical point because they will train the owners of the business and how to take better decisions and also improve their management skills. Al Mamun, Ibrahim, Yusoff, \& Fazal(2018) mention, these programs should aim to help them identify individual-enterprise level competitive advantages, key performance, and sustainability elements. This is because it has been proven that enhancing and improving the aspects of competitive advantage, performance, and sustainability among micro-enterprises should be able to increase their ability to withstand uncertainties that may take place in the future, apart from minimizing economic vulnerability.

The finding of this research could be a good reference for micro-enterprises who want to improve the way they are working and do not know how to start. 
Based on the results of this preliminary study, in 2019, a research project will start with one of the most important universities in Peru to analyze and prove in a more detailed study the suitability of the developed methodology in other micro-enterprises.

\section{Acknowledgment}

This research would not have been possible without the help of those who provided assistance and data, especially to the Engineers Susan Sacca Solano, Miguel Talla Chicoma, and Alfredo Talla Chicoma from Peru, their contribution was key in the elaboration of this paper.

\section{References}

[1] Al Mamun, Abdullah, Ibrahim, Mohamed, Yusoff, Mohd, \& Fazal, Syed. (2018). Entrepreneurial Leadership, Performance, and Sustainability of Micro-Enterprises in Malaysia. Sustainability, 10(5). doi:10.3390/su10051591

[2] ANDINA. (2018). Prices of fruits, vegetables and vegetables in retail markets should fall by $20 \%$, Ministery of Agriculture of Peru. EDITORA PERU.

[3] Beamon, Benita M. (1999). Measuring supply chain performance. 19(3), 275-292. doi:doi:10.1108/01443579910249714

[4] Bhamu, Jaiprakash, \& Singh Sangwan, Kuldip. (2014). Lean manufacturing: literature review and research issues. 34(7), 876-940. doi:doi:10.1108/IJOPM-08-2012-0315

[5] Bloom, Nicholas, Mahajan, Aprajit, McKenzie, David, \& Roberts, John. (2010). Why Do Firms in Developing Countries Have Low Productivity? American Economic Review, 100(2), 619-623. doi:doi: 10.1257/aer.100.2.619

[6] Damke, Elói Junior, Gimenez, Fernando Antonio Prado, \& Damke, Joice F. Wendling. (2018). Strategic configurations and performance: a study in micro and small business $\begin{array}{llll}\text { retailers. } & \text { RAUSP }\end{array}$ doi:https://doi.org/10.1016/j.rauspm.2017.12.005

[7] Gronroos, C. (2007). Service Management and Marketing: Customer Management in Service Competition: Wiley.

[8] Huang, Xueli. (2009). Strategic decision making in Chinese SMEs. 3(2), 87-101. doi:doi:10.1108/17506140910963602

[9] Hussain, Matloub, \& Malik, Mohsin. (2016). Prioritizing lean management practices in public and private hospitals. 30(3), 457-474. doi:doi:10.1108/JHOM-08-2014-0135

[10] Johnston, R., Clark, G., \& Shulver, M. (2012). Service Operations Management: Pearson Education Limited.

[11] Matt, D. T., \& Rauch, E. (2013). Implementation of Lean Production in Small Sized $\begin{array}{llll}\text { Enterprises. } & \text { Procedia } & \text { CIRP, } & 12,\end{array}$ doi:https://doi.org/10.1016/j.procir.2013.09.072 
[12] Message Costa, Luana Bonome, Filho, Moacir Godinho, Fredendall, Lawrence D., \& Gómez Paredes, Fernando José. (2018). Lean, six sigma and lean six sigma in the food industry: A systematic literature review. Trends in Food Science \& Technology. doi:https://doi.org/10.1016/j.tifs.2018.10.002

[13] Mohan Sharma, Kshitij, \& Lata, Surabhi. (2018). Effectuation of Lean Tool "5S" on Materials and Work Space Efficiency in a Copper Wire Drawing Micro-Scale Industry in India. Materials Today: Proceedings, 5(2, Part 1), 4678-4683. doi:https://doi.org/10.1016/j.matpr.2017.12.039

[14] Pearce, Antony, Pons, Dirk, \& Neitzert, Thomas. (2018). Implementing lean-Outcomes from SME case studies. Operations Research Perspectives, 5, 94-104. doi:https://doi.org/10.1016/j.orp.2018.02.002

[15] Sampson, Scott E., \& Froehle, Craig M. (2006). Foundations and Implications of a Proposed Unified Services Theory. 15(2), 329-343. doi:doi:10.1111/j.19375956.2006.tb00248.x

[16] Womack, J.P., \& Jones, D.T. (2010). Lean Thinking: Banish Waste and Create Wealth in Your Corporation: Free Press.

[17] Womack, James P. (1996). Lean thinking : banish waste and create wealth in your corporation: New York, NY : Simon \&amp; Schuster, [1996] (01996.

[18] Wu, Lin, Subramanian, Nachiappan, Abdulrahman, Muhammad, Liu, Chang, Lai, Keehung, \& Pawar, Kulwant. (2015). The Impact of Integrated Practices of Lean, Green, and Social Management Systems on Firm Sustainability Performance-Evidence from Chinese Fashion Auto-Parts Suppliers. 7(4), 3838.

[19] Zevallos, Elsa Esther Choy. (2010). Competitiveness of Micro and Small Companies in the presence of Free Trade Agreement (NAFTA). Quipukamayoc, Journal of Accounting Science, UNMSM, Lima, Perú, Vol. 17, 127-132. 